\title{
A Clinical Debate: What Is the Therapeutic Choice for Recurrent Graves' Hyperthyroidism?
}

\author{
Hengameh $\operatorname{Abdi}^{1}$, Seyed Rasoul Zakavi ${ }^{2,{ }^{*}}$ and Fereidoun Azizi ${ }^{1,{ }^{* *}}$ \\ ${ }^{1}$ Endocrine Research Center, Research Institute for Endocrine Sciences, Shahid Beheshti University of Medical Sciences, Tehran, Iran \\ ${ }^{2}$ Nuclear Medicine Research Center, Mashhad University of Medical Sciences, Mashhad, Iran \\ "Corresponding author: Nuclear Medicine Research Center, Mashhad University of Medical Sciences, Mashhad, Iran. Email: zakavir@mums.ac.ir \\ Corresponding author: Endocrine Research Center, Research Institute for Endocrine Sciences, Shahid Beheshti University of Medical Sciences, Tehran, Iran. Email: \\ azizi@endocrine.ac.ir
}

Received 2020 August 31; Revised 2020 September 26; Accepted 2020 September 29.

Keywords: Graves' Disease, Radioactive Iodine, Antithyroid Drug

\section{Introduction}

Hengameh Abdi, MD.

Ms. E.A. is a 36-year-old woman who has been referred for the management of recurrent hyperthyroidism. She was always healthy with no significant medical history until about 30 months ago when she developed signs and symptoms of hyperthyroidism with a 45-gm diffuse goiter. Laboratory test results were as follows: thyrotropin $(\mathrm{TSH})<0.01 \mathrm{mU} / \mathrm{L}$, free thyroxine (fT4): $42 \mathrm{pmol} / \mathrm{L}$ (normal range, 10 - $23 \mathrm{pmol} / \mathrm{L})$, TSH receptor antibodies (TRAb): $15.6 \mathrm{IU} / \mathrm{mL}$ (normal range, $<1.75 \mathrm{IU} / \mathrm{mL}$ ). She was treated with methimazole (MMI) via titration method, and thyroid hormone concentrations became normal within six weeks. She continued MMI 5 mg daily for 18 months; one year ago, she had a goiter weighing $30 \mathrm{gm}$ and following thyroid-related tests: TSH: $1.8 \mathrm{mU} / \mathrm{L}, \mathrm{fT} 4: 18 \mathrm{pmol} / \mathrm{L}$, serum $\mathrm{TRAb}=1.6 \mathrm{IU} / \mathrm{mL}$; MMI was discontinued, and she did well until one month ago (nearly eleven months after MMI discontinuation) when she experienced palpitation, tremor, anxiety, and insomnia and lost $3 \mathrm{~kg}$ of weight. Now, a diffuse goiter is evident; there are no symptoms or signs of Graves' orbitopathy. Recent serum TSH concentration is $0.06 \mathrm{mU} / \mathrm{L}$, serum fT4 is $42 \mathrm{pmol} / \mathrm{L}$, and serum TRAb is 11.6 $\mathrm{IU} / \mathrm{mL}$. According to this history and results of laboratory tests, she wants to know which therapeutic modality is recommended.

- Option 1: Recurrent Graves' hyperthyroidism should be treated with radioiodine.

- Option 2: Long-term methimazole is the treatment of choice for recurrent Graves' hyperthyroidism.

Herein, two experts, the first, a nuclear medicine specialist, and the second, a thyroidologist, defend their treat- ment choices based on the existing evidence and their own experience.

\section{Option 1: Recurrent Graves' Hyperthyroidism Should Be Treated with Radioiodine}

Seyed Rasoul Zakavi, MD.

Graves' disease (GD) is the most common cause of hyperthyroidism, which can be treated with three different options: antithyroid drugs (ATD), radioiodine therapy (RIT), and surgery (1). The RIT with I-131 has been the first choice in the primary treatment of GD in North America for many decades, while ATD has been preferred in the EU and Japan. A survey in 2011 showed that ATD was increasingly used in North America compared to previous decades, while in contrast, the use of radioiodine was increased in the eastern part of the globe $(1,2)$. National Institute for Health and Care Excellence (NICE) guideline-2019 recommends I-131 as the first-line therapy in the primary treatment of GD (3). The diverse pattern of preferences in different countries indicates that ATD and RIT have similar efficacy in controlling primary hyperthyroidism, and other factors may play a role in choosing the best treatment option (4). That is why the American Thyroid Association (ATA) guideline on diagnosis and management of hyperthyroidism in 2016 emphasizes patient values that may affect the choice of therapy (1). For recurrent GD, however, there are more consensus on the selection of definitive treatment, and European thyroid association (ETA)2018 and NICE-2019 guidelines recommend RIT in patients with recurrent $\operatorname{GD}(3,5)$.

In my opinion, RIT is the appropriate therapy in a 36year-old woman with recurrent GD who has previously 
been treated with methimazole for 18 months and experienced recurrence after one year with elevated TRAb and no ophthalmopathy. My recommendation for RIT in this patient is based on the following points:

1-ATD is not a definitive treatment for hyperthyroidism and recurrence following ATD has been reported in 40 $80 \%$ of the cases in different studies; the longer the followup time, the higher the chance of recurrence $(1,6)$. In a meta-analysis, including 26 randomized trials and involving 3,388 participants, the optimal duration of ATD therapy was 12 - 18 months, and the extension of ATD therapy did not provide any benefit in terms of the recurrence of hyperthyroidism (7). However, few publications mainly from a single center, reported that the administration of a low dose of methimazole for a longer time is associated with a higher rate of remission of hyperthyroidism $(8,9)$. Anyhow thionamids are associated with a variety of adverse effects, some of them are life-threatening (10). The list of complications of ATD is extensive and ranges from mild skin reactions to birth defects, fatal hepatitis, agranulocytosis and antineutrophil cytoplasmic antibodies (ANCA) vasculitis (1,11-14). A meta-analysis of 31 cohort studies showed that complications of ATD were seen in $13 \%$ of the patients; however, life-threatening complications were rare (15). Anyhow, 4\% of the cases with agranulocytosis, mostly within 90 days of ATD initiation, were fatal in a national database survey for adverse effects of ATD. The MMI dose ranged between 5 and $45 \mathrm{mg}$ in these fatal cases. Furthermore, they showed that agranulocytosis may happen after the second or subsequent exposure to ATD (16). So, lack of complication in the first course of therapy with ATD does not guarantee its safe use in the subsequent treatments. ATD-induced hepatotoxicity is another potentially fatal complication that may be seen with MMI and propylthiouracil (PTU) and may present as fulminant hepatitis with PTU (13). In the case under discussion, there is no compelling evidence that imposing another risk of complications, although rare, is justified, while there is a high chance of recurrence of the disease too. Moreover, this young patient may have a pregnancy in the future, which requires changing from MMI to PTU, imposing further risk of complication to the patient.

2- The RIT has been used for the treatment of GD for more than 70 years with no life-threatening complications (17). It is a highly effective treatment and a meta-analysis showed that treatment efficacy of RIT is much better and the complications are much less than ATD (15). It is the preferred therapy for recurrent GD, according to ETA and NICE guidelines $(3,5)$. The main complication of RIT is hypothyroidism, which is considered the goal of many guidelines $(1,5)$. Hypothyroidism can easily be treated with thyroid hormones without any complications, although lifelong administration of thyroid hormones is mandatory. The rate of hypothyroidism depends on the administered radioiodine dose, the higher the dose, the higher the chance of hypothyroidism (1). Different dose-dependent strategies of fixed versus individualized doses (based on thyroid radioiodine uptake and weight) have been used interchangeably in the past (18). Furthermore, both of these strategies can be applied using either low or high doses of radioiodine. Anyhow, it is shown that among fixed-dose strategies, radiation received by the thyroid is not related to the administered radioiodine dose $(19,20)$. Comparing different treatment modalities like ATD and RIT in terms of efficacy and complications requires the implementation of standard treatment in each arm. We have shown that individualized dose RIT is more effective than fixed-dose protocols and could treat patients with smaller doses of administered radioiodine and lower whole-body radiation (21).

3- Another complication is worsening or de novo occurrence of Graves' orbitopathy (GO) in at-risk patients that has been reported more commonly after RIT than thyroidectomy or ATD (22); however, the addition of steroid prophylaxis is an established, safe, and effective way to prevent worsening of GO $(23,24)$. Although there are reports that higher doses of radioiodine (300 Gy versus $200 \mathrm{~Gy}$ ) may have a better outcome in terms of GO (25), we have shown for the first time that an individualized dose of I-131 with $5.55 \mathrm{MBq} / \mathrm{gr}$ of thyroid weight is associated with the lowest risk of worsening of GO compared to fixed-dose protocols (21). We hypothesized that RIT using fixed-dose radioiodine may be associated with over destruction of the thyroid tissue and antigen release that may be associated with worsening of GO. However, de novo GO after RIT is rare, and there is no randomized clinical trial indicating that the long-term outcome of mild GO is better using ATD compared to definitive treatment (5). Also, treatment for hyperthyroidism is unlikely to cause ocular changes and, therefore, is chosen irrespective of GO (26). In the patient under debate, with regard to the lack of GO, no steroid prophylaxis is needed before RIT, and we do not expect to have de novo GO after RIT. Other complications of RIT, such as neck pain or swelling and transient worsening of thyrotoxicosis after RIT, are more common in patients with large multinodular goiter that is not the case in our patient.

4- Cardiovascular diseases are the most common cause of death in patients with hyperthyroidism. The GD is associated with increased mortality, and it is shown that mortality in GD is dependent on the cumulative period of suppressed TSH levels $(27,28)$. A large cohort study with 20,651 cardiovascular death in hyperthyroid patients showed that increased cardiovascular risk was driven by insufficient treatment of hyperthyroidism (29). Another cohort study confirmed that effective control of hyperthy- 
roidism is associated with lower cardiovascular mortality, so rapid and sustained control of hyperthyroidism should be prioritized in the management of GD(30). Relapse of hyperthyroidism is more common with ATD, and periods of hyperthyroidism and hypothyroidism could be detrimental and could result in higher cardiovascular and overall mortality (28). Three different studies revealed a higher overall mortality rate in patients treated with ATD compared to patients treated with RIT (30-32). Interestingly, the mortality was $50 \%$ lower in patients who were successfully treated with RIT and not in patients with treatment failure, underpinning the importance of effective control of hyperthyroidism (30). Recently, an observational study looking at the data from patients with GD who had been treated with RIT from the mid-1940s to mid-1960s has suggested excess cancer-related mortality in radioiodine treated cohorts compared to the background population. However, the study has major drawbacks as dosimetric data were available in only 197 patients and extrapolated to all others (33). The interpretation of this study is severely constrained by study design that included multiple dosimetric assumptions that might not be correct, no adjustment for relevant cancer risk factors like smoking, obesity, or thyroid hormone status, and no ATD control group. So, the study could not distinguish the effect of treatment from the disease itself. Interestingly, one of the co-authors of the same article published additional analysis from the same dataset by addition of hyperthyroid patients treated with ATD as a control group and, in direct contrast, found excess cancer mortality in patients treated exclusively with ATD and not in patients treated with RIT (34). This finding is consistent with previous reports of cancer-related mortality in patients treated with ATD (35). Although the association of cancer with ATD therapy has been reported, it seems that cancer-related mortality is more associated with uncontrolled hyperthyroidism rather than the therapy modality itself (15). So, effective control of hyperthyroidism should be the main focus of the treatment of GD, which is better achieved with RIT (15).

5- Another issue that should be discussed is the quality of life and cost-effectiveness of different treatment options. According to the NICE guideline on the management of hyperthyroidism, RIT is more cost-effective than surgery or ATD for the treatment of adult patients with GD (3). While reports from England, Australia, and Germany showed that RIT was least expensive and/or most cost-effective in the primary treatment of GD, not all publications from the USA were confirmatory (36-39). Furthermore, the cost-utility analysis of RIT compared with ATD in Japan, considering all medical costs for 40 years following treatment, showed that RIT is superior to ATD in patients with GD (40). In a 14 - 21 year follow-up in Sweden, health- related quality of life(HRQL) of patients who were randomized for treatment with ATD, RIT, or surgery were assessed using SF36 and QoL2004, and it was not significantly different (41). Although in a sub-cohort survey, patients treated with ATD or thyroidectomy had better thyroid-related and general QoL compared to those received RIT, the sick leave from work was not different between the three treatment modalities (42).

In conclusion, it is our responsibility as physicians to explain in simple words to the patients the advantages and complications of each therapy option and share them in choosing the appropriate treatment. This approach requires that physicians spend enough time, have up to date knowledge, and avoid any potential conflict of interest. However, as this clinical debate indicates, practically, it may turn to a physicians' choice rather than patients' choice. For me, it is safer to take lifelong levothyroxine than long-term methimazole, and I recommend radioiodine for recurrent GD in this patient as a more effective modality with no life-threatening complication, lower costs, and probably lower chance of death.

\section{Option 2: Long-term Methimazole is the Treatment of Choice for Recurrent Graves' Hyperthyroidism.}

\section{Fereidoun Azizi, MD.}

Graves' disease (GD) is caused by a complex interaction of genetic and environmental risk factors; it is a common disease with a prevalence of $1-1.5 \%$ in the general population. Its natural course is prolonged with relapsing and remitting episodes of hyperthyroidism for many years. In this autoimmune disease, TRAb stimulates TSH receptors of thyrocytes and causes hyperthyroidism (43).

The introduction of two modes of treatment for hyperthyroidism in 1940s, thionamide ATD through inhibition of thyroid hormone synthesis and radioactive iodine (RAI) therapy via ablation of thyroid tissue, have been considered as great progress for management of GD (44). However, none of these therapeutic approaches or thyroidectomy has been able to re-establish normal lifelong thyroid function in all patients permanently (45). RAI and surgery cause hypothyroidism for the rest of the patient's life, and conventional 12-18 months of ATD treatment has a risk of 20 - 70\% (average 50\%) relapse upon ATD withdrawal (1).

The ATD has been the treatment of choice for hyperthyroidism in Europe, Japan, and Latin America, while physicians in the US preferred RAI treatment for Graves' hyperthyroidism for many decades (46). This attitude has been changed in the last decade, and ATD has become the first treatment choice in the US, as well (47). Since ATD has become the preferred treatment of newly diagnosed Graves' 
patients in many countries of the world, the major question is which mode of treatment is advisable for $50 \%$ of patients who experience the relapse of hyperthyroidism after ATD withdrawal; such patients may have a choice of RAI and thyroidectomy or re-institution of ATD treatment with long-term duration (48).

Subtotal thyroidectomy is accompanied by $29 \%$ persistent or recurrent hyperthyroidism and 50\% hypothyroidism, resulting in only 19\% euthyroidism after 6 years of follow-up (49). Therefore, both ATA and ETA recommend total thyroidectomy as the preferred mode of surgery for $\mathrm{GD}$, which results in permanent hypothyroidism in the majority of patients $(1,5)$. Considering other worrisome, although rare, complications of recurrent nerve injury, hypoparathyroidism, and peri-operative adverse events, I do not recommend total thyroidectomy to Ms. E.A.

The reported rate of recurrent hyperthyroidism after sub-ablative doses of RAI is 61-69\% (50). Administration of ablative doses of RAI cause 77,17, and 6\% hypo-, hyper-, and euthyroidism at one year, respectively, and $14 \%$ require the second RAI dose. 80 months after RAI treatment, 86, 3.2, and 3.3\% of patients became hypo-, hyper-, and euthyroid, and $6.4 \%$ died (51). It has recently been reported that in RAItreated patients with hyperthyroidism, the risk of death from solid cancer increases (33); however, the study has some limitations. Regarding cardiovascular disease as the major cause of death in hyperthyroid patients, it is related to the cumulative period of suppressed serum $\operatorname{TSH}(28,29)$. A head to head trial comparing efficacy and side effects of ATD versus RAI therapy have shown a higher occurrence of suppressed TSH in RAI treated hyperthyroid patients on levothyroxine, as compared to patients on long-term ATD (LT-ATD) therapy (52), a finding which may increase the risk of death in RAI-treated patients with GD.

Both ablative RAI doses and total thyroidectomy create another disease, i.e., hypothyroidism, requiring lifelong thyroid hormone replacement in the majority of patients. Levothyroxine therapy may accompany lower triiodothyronine to $\mathrm{T} 4$ ratio, higher body mass index, serum lipid derangements, lower resting energy expenditure, and impairment of psychological well-being compared to normal controls or euthyroid Graves' patients (53-57). In addition, the most recent evaluation of the quality of life has shown greater impairment of both thyroid-specific and general quality of life scores in RAI-treated patients compared to those treated with ATD or surgery (42).

For decades after the ATD introduction for treatment of hyperthyroidism, it was believed that 12-18 months is the optimal duration of therapy, and increasing the duration of ATD therapy would not increase the remission rate after drug withdrawal $(7,58)$. The effectiveness of continuous LT-ATD treatment for Graves' hyperthyroidism was intro- duced in 2005 (52). Recently, few other studies have also reported higher remission rates with LT-ATD treatment (5961), and two systematic reviews and meta-analyses showed efficacy (8) and safety of LT-ATD therapy(62). More recently, it was shown that methimazole (MMI) therapy of patients with GD for 60 - 120 months is effective and safe and only 8 and 16\% of patients experience a relapse of hyperthyroidism 12 and 48 months after discontinuation of MMI, respectively (9). Similar findings were reported in patients with Juvenile GD $(63,64)$.

Based on the results of one of the largest cohort of ATD treated patients with GD, in many patients, serum TRAb concentration may become normal after conventional ATD therapy but will fluctuate after discontinuation of ATD, and remission of GD occurs after 4 - 11 years (median 6.8 years) of ATD therapy (65). These findings point to the importance of LT-ATD treatment to ensure a higher probability of remission. In Ms. E.A., serum TRAb concentration was $1.6 \mathrm{IU} / \mathrm{mL}$ at the end of the first course of MMI therapy; however, she experienced a recurrence of hyperthyroidism after MMI withdrawal. Relapse of hyperthyroidism occurs in $80-100 \%$ of patients with persistent high TRAb levels and $20-30 \%$ of those with low or undetectable TRAb; however, $64 \%$ of Graves' patients have TRAb titers of $1.5-10 \mathrm{IU} / \mathrm{mL}$ at the end of conventional ATD treatment, and $40-80 \%$ of these patients may have a recurrence of hyperthyroidism after discontinuation of ATD therapy $(66,67)$.

I recommend Ms. E.A. to choose long-term MMI for control of her disease. This advice is based on the following evidence-based data, as compared to RAI treatment (68):

1. More sustained euthyroidism (52, 59-61);

2. Less variations in serum TSH concentrations $(9,52$, $60)$;

3. Lower occurrences of both subclinical and clinical hypo- and hyperthyroidism $(9,52,60,61)$;

4. Less chance of developing orbitopathy $(61,69)$;

5. Better lipid profile and body mass index $(53,57)$;

6 . Better quality of life $(42,52)$;

7. Similar or lower overall medical cost $(52,60)$;

8. Rare drug adverse effects during ATD therapy with a low maintenance dose of MMI (70).

In conclusion, the 2016 ATA guidelines state that if a patient becomes hyperthyroid after conventional $12-18$ months of ATD therapy, RAI or thyroidectomy should be considered, and continuous low dose MMI may be adopted in patients, not in remission (persistently high TRAb). More recent clinical studies have shown that LT-ATD treatment is safe and provides control of hyperthyroidism without replacing it with hypothyroidism. In addition, LT-ATD treatment of $>5$ years is accompanied by a cure of disease in $86 \%$ of Graves' patients after ATD withdrawal. Therefore, this mode of therapy has become another effective 
and safe treatment for patients with relapse of Graves' hyperthyroidism. It is noteworthy that Graves' disease requires lifelong follow-up because of the possibility of recurrence of hyperthyroidism and the occurrence of spontaneous hypothyroidism (48). Therefore, physicians and patients should consider the natural course of GD and the benefits and adverse events of each therapeutic approach to select the most suitable treatment modality for each particular patient.

\section{Footnotes}

Authors' Contribution: F.A. and H.A. developed the original idea; each author wrote his/her related section of the manuscript. All authors read and approved the final draft. F.A. and S.R.Z. contributed equally to this article.

Conflict of Interests: Authors have no financial interests related to the material in the manuscript.

Funding/Support: The authors declare no funding/support related to the manuscript.

\section{References}

1. Ross DS, Burch HB, Cooper DS, Greenlee MC, Laurberg P, Maia AL, et al. 2016 american thyroid association guidelines for diagnosis and management of hyperthyroidism and other causes of thyrotoxicosis. Thyroid.2016;26(10):1343-421. doi: 10.1089/thy.2016.0229. [PubMed: 27521067].

2. Burch HB, Burman KD, Cooper DS. A 2011 survey of clinical practice patterns in the management of Graves' disease. J Clin Endocrinol Metab. 2012;97(12):4549-58. doi: 10.1210/jc.2012-2802. [PubMed: 23043191].

3. National Guideline Centre. Thyroid disease: assessment and management. London: NICE guideline; 2019.

4. Okosieme OE, Taylor PN, Dayan CM. Should radioiodine now be first line treatment for Graves' disease? Thyroid Res. 2020;13:3. doi: 10.1186/s13044-020-00077-8. [PubMed: 32165924]. [PubMed Central: PMC7061474].

5. Kahaly GJ, Bartalena L, Hegedus L, Leenhardt L, Poppe K, Pearce SH. 2018 european thyroid association guideline for the management of graves' hyperthyroidism. Eur Thyroid J. 2018;7(4):167-86. doi: 10.1159/000490384. [PubMed: 30283735]. [PubMed Central: PMC6140607].

6. Menéndez Torre E, Anda Apiñaniz E, Barbería Layana JJ, Valdés Gallego N, Rabal Artal A, Díaz-Cadórniga F, et al. [Recurrence and prognostic factors after treatment with antithyroid agents in GravesBasedow disease. Multicenter study in Northern Spain]. Revista Clínica Española. 2000;200(2):69-73. Espanish. doi: 10.1016/s00142565(00)70566-2.

7. Abraham P, Avenell A, McGeoch SC, Clark LF, Bevan JS. Antithyroid drug regimen for treating Graves' hyperthyroidism. Cochrane Database Syst Rev. 2010;(1). CD003420. doi: 10.1002/14651858.CD003420.pub4. [PubMed: 20091544]. [PubMed Central: PMC6599817].

8. Azizi F, Malboosbaf R. Long-term antithyroid drug treatment: A systematic review and meta-analysis. Thyroid. 2017;27(10):1223-31. doi: 10.1089/thy.2016.0652. [PubMed: 28699478].

9. Azizi F, Amouzegar A, Tohidi M, Hedayati M, Khalili D, Cheraghi L, et al. Increased remission rates after long-term methimazole therapy in patients with Graves' disease: Results of a randomized clinical trial.
Thyroid. 2019;29(9):1192-200. doi: 10.1089/thy.2019.0180. [PubMed: 31310160].

10. Abdi H, Amouzegar A, Azizi F. Antithyroid drugs. Iran J Pharm Res. 2019;18(Suppl1):1-12. doi: 10.22037/ijpr.2020.112892.14005. [PubMed: 32802086]. [PubMed Central: PMC7393052].

11. Escobar-Morreale HF, Bravo P, Garcia-Robles R, Garcia-Larana J, de la Calle H, Sancho JM. Methimazole-induced severe aplastic anemia: unsuccessful treatment with recombinant human granulocytemonocyte colony-stimulating factor. Thyroid. 1997;7(1):67-70. doi: 10.1089/thy.1997.7.67. [PubMed: 9086574].

12. Hacking S, Uppal NN, Khan N, Ionescu M, Bijol V. Systemic p-ANCA vasculitis with fatal outcome, arising in the setting of methimazole use. Clin Nephrol Case Stud. 2019;7:23-6. doi: 10.5414/CNCS109759. [PubMed: 31008018]. [PubMed Central: PMC6470634].

13. Schwab GP, Wetscher GJ, Vogl W, Redmond E. Methimazole-induced cholestatic liver injury, mimicking sclerosing cholangitis. Langenbecks Arch Chir. 1996;381(4):225-7. doi: 10.1007/BF00571690. [PubMed: 8817448].

14. Watanabe N, Narimatsu H, Noh JY, Yamaguchi T, Kobayashi K, Kami $\mathrm{M}$, et al. Antithyroid drug-induced hematopoietic damage: a retrospective cohort study of agranulocytosis and pancytopenia involving 50,385 patients with Graves' disease. J Clin Endocrinol Metab. 2012;97(1):E49-53. doi: 10.1210/jc.2011-2221. [PubMed: 22049174].

15. Sundaresh V, Brito JP, Wang Z, Prokop LJ, Stan MN, Murad MH, et al. Comparative effectiveness of therapies for Graves' hyperthyroidism: a systematic review and network meta-analysis. J Clin Endocrinol Metab.2013;98(9):3671-7. doi:10.1210/jc.2013-1954. [PubMed: 23824415]. [PubMed Central: PMC3763977].

16. Nakamura H, Miyauchi A, Miyawaki N, Imagawa J. Analysis of 754 cases of antithyroid drug-induced agranulocytosis over 30 years in Japan. J Clin Endocrinol Metab. 2013;98(12):4776-83. doi: 10.1210/jc.2013-2569. [PubMed: 24057289].

17. Bonnema SJ, Hegedus L. Radioiodine therapy in benign thyroid diseases: effects, side effects, and factors affecting therapeutic outcome. Endocr Rev. 2012;33(6):920-80. doi: 10.1210/er.2012-1030. [PubMed: 22961916].

18. Silberstein EB, Alavi A, Balon HR, Clarke SE, Divgi C, Gelfand MJ, et al. The SNMMI practice guideline for therapy of thyroid disease with 131I 3.0. J Nucl Med. 2012;53(10):1633-51. doi: 10.2967/jnumed.112.105148. [PubMed: 22787108].

19. Willegaignon J, Sapienza MT, Coura-Filho GB, Watanabe T, Traino AC, Buchpiguel CA. Graves' disease radioiodine-therapy: choosing target absorbed doses for therapy planning. Med Phys. 2014;41(1):12503. doi: 10.1118/1.4846056. [PubMed: 24387527].

20. Hammes J, van Heek L, Hohberg M, Reifegerst M, Stockter S, Dietlein $\mathrm{M}$, et al. Impact of different approaches to calculation of treatment activities on achieved doses in radioiodine therapy of benign thyroid diseases. EJNMMI Phys. 2018;5(1):32. doi: 10.1186/s40658-018-0231-x. [PubMed: 30539323]. [PubMed Central: PMC6289932].

21. Ariamanesh S, Ayati N, Mazloum Khorasani Z, Mousavi Z, Kiavash V, Kiamanesh Z, et al. Effect of different 131I dose strategies for treatment of hyperthyroidism on Graves' ophthalmopathy. Clin Nucl Med. 2020;45(7):514-8. doi: 10.1097/RLU.0000000000003086. [PubMed: 32433165].

22. Tallstedt L, Lundell G, Torring O, Wallin G, Ljunggren JG, Blomgren $\mathrm{H}$, et al. Occurrence of ophthalmopathy after treatment for Graves' hyperthyroidism. The thyroid study group. $N$ Engl J Med. 1992;326(26):1733-8. doi: 10.1056/NEJM199206253262603. [PubMed: 1489388].

23. Rosetti S, Tanda ML, Veronesi G, Masiello E, Premoli P, Gallo D, et al. Oral steroid prophylaxis for Graves' orbitopathy after radioactive iodine treatment for Graves' disease is not only effective, but also safe. J Endocrinol Invest. 2020;43(3):381-3. doi: 10.1007/s40618-019-01126-2. [PubMed: 31587179]. 
24. Vannucchi G, Covelli D, Campi I, Curro N, Dazzi D, Rodari M, et al. Prevention of orbitopathy by oral or intravenous steroid prophylaxis in short duration graves' disease patients undergoing radioiodine ablation: A prospective randomized control trial study. Thyroid. 2019;29(12):1828-33. doi: 10.1089/thy.2019.0150. [PubMed: 31860407].

25. Gosmann J, Willms D, Bell E, Schreckenberger M, Willms A. Improving treatment outcomes for Graves' disease patients with inactive forms of Graves' orbitopathy through an increased dose of radioiodine therapy. Nuklearmedizin. 2020;59(3):260-8. doi: 10.1055/a-11498552. [PubMed: 32403138].

26. Bartalena L, Macchia PE, Marcocci C, Salvi M, Vermiglio F. Effects of treatment modalities for Graves' hyperthyroidism on Graves' orbitopathy: a 2015 Italian Society of Endocrinology Consensus Statement. J Endocrinol Invest. 2015;38(4):481-7. doi: 10.1007/s40618-0150257-z. [PubMed: 25722226]. [PubMed Central: PMC4374116].

27. Brandt F, Thvilum M, Almind D, Christensen K, Green A, Hegedus L, et al. Graves' disease and toxic nodular goiter are both associated with increased mortality but differ with respect to the cause of death: a Danish population-based register study. Thyroid. 2013;23(4):408-13. doi: 10.1089/thy.2012.0500. [PubMed: 23253072].

28. Lillevang-Johansen M, Abrahamsen B, Jorgensen HL, Brix TH, Hegedus L. Excess mortality in treated and untreated hyperthyroidism is related to cumulative periods of low serum TSH.J Clin Endocrinol Metab. 2017;102(7):2301-9. doi: 10.1210/jc.2017-00166. [PubMed: 28368540].

29. Lillevang-Johansen M,Abrahamsen B, Jorgensen HL, Brix TH, Hegedus L. Duration of hyperthyroidism and lack of sufficient treatment are associated with increased cardiovascular risk. Thyroid. 2019;29(3):33240. doi: 10.1089/thy.2018.0320. [PubMed: 30648498].

30. Okosieme OE, Taylor PN, Evans C, Thayer D, Chai A, Khan I, et al. Primary therapy of Graves' disease and cardiovascular morbidity and mortality: a linked-record cohort study. Lancet Diabetes Endocrinol. 2019;7(4):278-87. doi: 10.1016/S2213-8587(19)30059-2. [PubMed: 30827829].

31. Boelaert K, Maisonneuve P, Torlinska B, Franklyn JA. Comparison of mortality in hyperthyroidism during periods of treatment with thionamides and after radioiodine. J Clin Endocrinol Metab. 2013;98(5):1869-82. doi: 10.1210/jc.2012-3459. [PubMed: 23543662].

32. Gronich N, Lavi I, Rennert G, Saliba W. Cancer risk after radioactive iodine treatment for hyperthyroidism: A cohort study. Thyroid. 2020;30(2):243-50. doi: 10.1089/thy.2019.0205. [PubMed: 31880205].

33. Kitahara CM, Berrington de Gonzalez A, Bouville A, Brill AB, Doody MM, Melo DR, et al. Association of radioactive iodine treatment with cancer mortality in patients with hyperthyroidism. JAMA Intern Med. 2019. doi: 10.1001/jamainternmed.2019.0981. [PubMed: 31260066]. [PubMed Central: PMC6604114].

34. Tulchinsky M, Brill AB. Spotlight on the association of radioactive iodine treatment with cancer mortality in patients with hyperthyroidism is keeping the highest risk from antithyroid drugs in the blind spot. Clin Nucl Med. 2019;44(10):789-91. doi: 10.1097/RLU.0000000000002792. [PubMed: 31453816].

35. Ron E, Doody MM, Becker DV, Brill AB, Curtis RE, Goldman MB, et al. Cancer mortality following treatment for adult hyperthyroidism. Cooperative Thyrotoxicosis Therapy Follow-up Study Group. JAMA. 1998;280(4):347-55. doi: 10.1001/jama.280.4.347. [PubMed: 9686552].

36. Patel NN, Abraham P, Buscombe J, Vanderpump MP. The cost effectiveness of treatment modalities for thyrotoxicosis in a U.K. center. Thyroid. 2006;16(6):593-8. doi: 10.1089/thy.2006.16.593. [PubMed: 16839261].

37. Donovan PJ, McLeod DS, Little R, Gordon L. Cost-utility analysis comparing radioactive iodine, anti-thyroid drugs and total thyroidectomy for primary treatment of Graves' disease. Eur J Endocrinol. 2016;175(6):595-603. doi: 10.1530/EJE-16-0527. [PubMed: 27634939].

38. In H, Pearce EN, Wong AK, Burgess JF, McAneny DB, Rosen JE. Treatment options for Graves disease: a cost-effectiveness analysis.JAm Coll Surg. 2009;209(2):170-179 e1-2. doi:10.1016/j.jamcollsurg.2009.03.025. [PubMed: 19632593].
39. Dietlein M, Moka D, Schmidt M, Theissen P, Schicha H. [Prevention, screening and therapy of thyroid diseases and their costeffectiveness]. Nuklearmedizin. 2003;42(5):181-9. [PubMed: 14571314].

40. Hayashi K, Abe K, Sakata I, Sakaguchi C, Yamamoto K, Kosuda S. [Costutility analysis of antithyroid drug therapy versus 131I therapy for Graves' disease]. Kaku Igaku. 2005;42(2):87-95. [PubMed: 16038427].

41. Abraham-Nordling M, Wallin G, Lundell G, Torring O. Thyroid hormone state and quality of life at long-term follow-up after randomized treatment of Graves' disease. Eur J Endocrinol. 2007;156(2):173-9. doi: 10.1530/eje.1.02336. [PubMed: 17287406].

42. Torring $\mathrm{O}$, Watt $\mathrm{T}$, Sjolin $\mathrm{G}$, Bystrom K, Abraham-Nordling $\mathrm{M}$, Calissendorff $\mathrm{J}$, et al. Impaired quality of life after radioiodine therapy compared to antithyroid drugs or surgical treatment for graves' hyperthyroidism: A long-term follow-up with the thyroidrelated patient-reported outcome questionnaire and 36-item short form health status survey. Thyroid. 2019;29(3):322-31. doi: 10.1089/thy.2018.0315. [PubMed: 30667296].

43. Smith TJ, Hegedus L. Graves' disease. NEngl J Med. 2016;375(16):1552-65 doi: 10.1056/NEJMra1510030. [PubMed: 27797318].

44. Abdi H, Amouzegar A. Management of Graves' Hyperthyroidism: More Than a Century of Progression. Intl J Endocrinol Metab. 2020;18(Suppl). doi: 10.5812/ijem.103943.

45. Allannic H, Fauchet R, Orgiazzi J, Madec AM, Genetet B, Lorcy Y, et al. Antithyroid drugs and Graves' disease: a prospective randomized evaluation of the efficacy of treatment duration. J Clin Endocrinol Metab. 1990;70(3):675-9. doi: 10.1210/jcem-70-3-675. [PubMed: 1689737].

46. Wartofsky L, Glinoer D, Solomon B, Nagataki S, Lagasse R, Nagayama Y, et al. Differences and similarities in the diagnosis and treatment of Graves' disease in Europe, Japan, and the United States. Thyroid. 1991;1(2):129-35. doi: 10.1089/thy.1991.1.129. [PubMed:1688014].

47. Brito JP, Payne S, Singh Ospina N, Rodriguez-Gutierrez R, Maraka $S$, Sangaralingham LR, et al. Patterns of use, efficacy, and safety of treatment options for patients with graves' disease: A nationwide population-based study. Thyroid. 2020;30(3):357-64. doi: 10.1089/thy.2019.0132. [PubMed: 31973681].

48. Azizi F. Long-term treatment of hyperthyroidism with antithyroid drugs: 35 years of personal clinical experience. Thyroid. 2020;30(10):1451-7. doi: 10.1089/thy.2019.0814. [PubMed: 32253999].

49. Lin YS, Lin JD, Hsu CC, Yu MC. The long-term outcomes of thyroid function after subtotal thyroidectomy for Graves' hyperthyroidism. J Surg Res. 2017;220:112-8. doi: 10.1016/j.jss.2017.06.091. [PubMed: 29180171].

50. Bonnema SJ, Bennedbaek FN, Veje A, Marving J, Hegedus L. Propylthiouracil before 131I therapy of hyperthyroid diseases: effect on cure rate evaluated by a randomized clinical trial. J Clin Endocrinol Metab. 2004;89(9):4439-44. doi: 10.1210/jc.2004-0247. [PubMed: 15356044].

51. Aung ET, Zammitt NN, Dover AR, Strachan MWJ, Seckl JR, Gibb FW. Predicting outcomes and complications following radioiodine therapy in Graves' thyrotoxicosis. Clin Endocrinol (Oxf). 2019;90(1):192-9. doi: 10.1111/cen.13873. [PubMed: 30291728].

52. Azizi F, Ataie L, Hedayati M, Mehrabi Y, Sheikholeslami F. Effect of long term continuous methimazole treatment of hyperthyroidism: comparison with radioiodine. Eur J Endocrinol. 2005;152(5):695-701. doi: 10.1530/eje.1.01904. [PubMed: 15879354].

53. Peterson SJ, McAninch EA, Bianco AC. Is a normal tsh synonymous with "euthyroidism" in levothyroxine monotherapy? J Clin Endocrinol Metab. 2016;101(12):4964-73. doi: 10.1210/jc.2016-2660. [PubMed: 27700539]. [PubMed Central: PMC6287526].

54. Samuels MH, Kolobova I, Smeraglio A, Peters D, Purnell JQ, Schuff KG. Effects of levothyroxine replacement or suppressive therapy on energy expenditure and body composition. Thyroid. 2016;26(3):34755. doi: 10.1089/thy.2015.0345. [PubMed: 26700485]. [PubMed Central: PMC4790206].

55. McAninch EA, Rajan KB, Miller $\mathrm{CH}$, Bianco AC. Systemic thyroid hormone status during levothyroxine therapy in hypothyroidism: A 
systematic review and meta-analysis. J Clin Endocrinol Metab. 2018. doi: 10.1210/jc.2018-01361. [PubMed: 30124904]. [PubMed Central: PMC6226605].

56. Saravanan P, Chau WF, Roberts N, Vedhara K, Greenwood R, Dayan CM. Psychological well-being in patients on 'adequate' doses of l-thyroxine: results of a large, controlled community-based questionnaire study. Clin Endocrinol (Oxf). 2002;57(5):577-85. doi: 10.1046/j.1365-2265.2002.01654.x. [PubMed: 12390330].

57. Azizi F, Amouzegar A, Tohidi M, Hedayati M, Cheraghi L, Mehrabi Y. Systemic thyroid hormone status in treated Graves' disease. Int J Endocrinol Metab. 2019;17(4). e95385. doi: 10.5812/ijem.95385. [PubMed: 31998382]. [PubMed Central: PMC6942169].

58. Maugendre D, Gatel A, Campion L, Massart C, Guilhem I, Lorcy Y, et al. Antithyroid drugs and Graves' disease-prospective randomized assessment of long-term treatment. Clin Endocrinol (Oxf).1999;50(1):12732. doi:10.1046/j.1365-2265.1999.00629.x. [PubMed:10341866].

59. Laurberg P, Berman DC, Andersen S, Bulow Pedersen I. Sustained control of Graves' hyperthyroidism during long-term low-dose antithyroid drug therapy of patients with severe Graves' orbitopathy. Thyroid 2011;21(9):951-6. doi: 10.1089/thy.2011.0039. [PubMed: 21834677].

60. Azizi F, Yousefi V, Bahrainian A, Sheikholeslami F, Tohidi M, Mehrabi Y. Long-term continuous methimazole or radioiodine treatment for hy perthyroidism. Arch Iran Med. 2012;15(8):477-84. [PubMed: 22827783].

61. Villagelin D, Romaldini JH, Santos RB, Milkos AB, Ward LS. Outcomes in relapsed Graves' disease patients following radioiodine or prolonged low dose of methimazole treatment. Thyroid. 2015;25(12):128290. doi: 10.1089/thy.2015.0195. [PubMed: 26414885].

62. Azizi F, Malboosbaf R. Safety of long-term antithyroid drug treatment? A systematic review. J Endocrinol Invest. 2019;42(11):1273-83. doi: 10.1007/s40618-019-01054-1. [PubMed: 31134536].

63. Leger J, Gelwane G, Kaguelidou F, Benmerad M, Alberti C, French Childhood Graves' Disease Study G. Positive impact of long-term an- tithyroid drug treatment on the outcome of children with Graves' disease: national long-term cohort study. J Clin Endocrinol Metab. 2012;97(1):110-9. doi: 10.1210/jc.2011-1944. [PubMed: 22031519].

64. Azizi F, Takyar M, Madreseh E, Amouzegar A. Long-term methimazole therapy in juvenile Graves' disease: A randomized trial.Pediatrics. 2019;143(5). doi: 10.1542/peds.2018-3034. [PubMed: 31040197].

65. Okamura K, Bandai S, Fujikawa M, Sato K, Ikenoue H, Kitazono T. Longterm antithyroid drug treatment: Trends in serum TSH and TSH receptor antibody changes in patients with Graves' disease. Int J Endocrinol Metab. 2020;18(Suppl). doi: 10.5812/ijem.101139.

66. Carella C, Mazziotti G, Sorvillo F, Piscopo M, Cioffi M, Pilla P, et al. Serum thyrotropin receptor antibodies concentrations in patients with Graves' disease before, at the end of methimazole treatment, and after drug withdrawal: evidence that the activity of thyrotropin receptor antibody and/or thyroid response modify during the observation period. Thyroid. 2006;16(3):295-302. doi: 10.1089/thy.2006.16.295. [PubMed: 16571093].

67. Quadbeck B, Hoermann R, Roggenbuck U, Hahn S, Mann K, Janssen $\mathrm{OE}$, et al. Sensitive thyrotropin and thyrotropin-receptor antibody determinations one month after discontinuation of antithyroid drug treatment as predictors of relapse in Graves' disease. Thyroid. 2005;15(9):1047-54. doi: 10.1089/thy.2005.15.1047. [PubMed:16187913].

68. Azizi F. A new perspective in the management of Graves' hyperthyroidism. Int $J$ Endocrinol Metab. 2020;18(Suppl). doi: 10.5812/ijem.102270.

69. Ma C, Xie J, Wang H, Li J, Chen S. Radioiodine therapy versus antithyroid medications for Graves' disease. Cochrane Database Syst Rev. 2016;2. CD010094. doi: 10.1002/14651858.CD010094.pub2. [PubMed: 26891370].

70. Malboosbaf R, Azizi F. Long-term treatment with antithyroid drugs: Efficacy and safety. Int J Endocrinol Metab. 2020;18(Suppl). doi: 10.5812/ijem.101487. 